\title{
Molecular foundations of Precambrian uniformitarianism
}

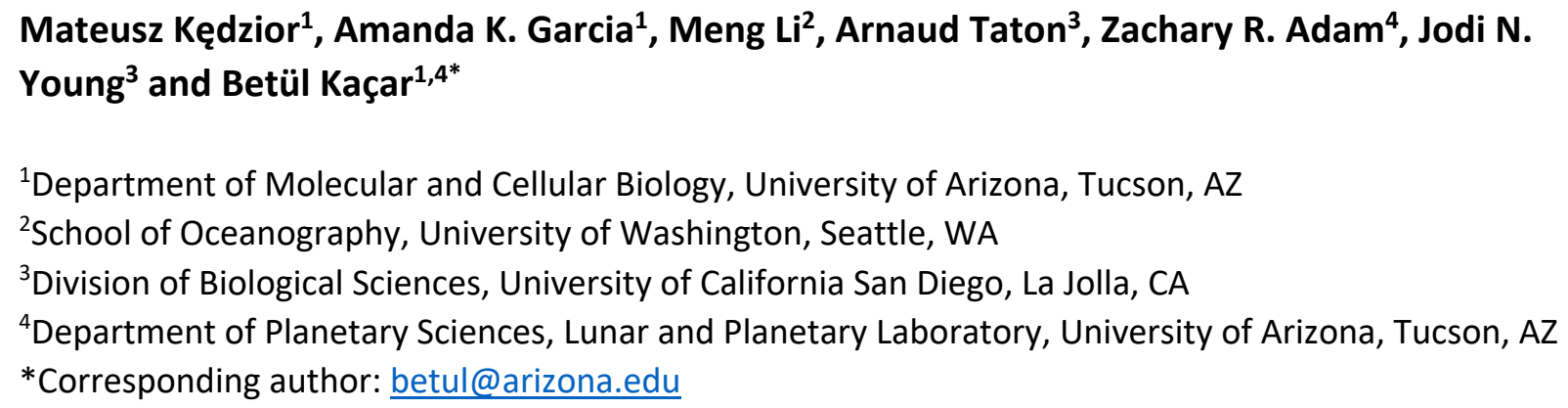

Keywords: RuBisCO, carbon fixation, carbon isotope record, molecular paleobiology, paleogenetics, ancestral sequence reconstruction

\begin{abstract}
Uniformitarian assumptions underlie the oldest evidence for living organisms on Earth, the distinct isotope fractionation between inorganic and organic carbon. Aside from a handful of compelling deviations, the ${ }^{13} \mathrm{C} /{ }^{12} \mathrm{C}$ isotopic mean of preserved organic carbon $\left(\delta^{13} \mathrm{C}\right.$ org $)$ has remained remarkably unchanged through time. RuBisCO is the principal carboxylase/oxygenase biomolecular component that is thought to primarily account for the generation of these distinct carbon isotopic signals. However, it is difficult to reconcile a mostly unchanging mean $\delta^{13} \mathrm{C}_{\text {org }}$ with several known factors that can affect the isotope fractionation of RuBisCO, such as atmospheric composition and the amino acid composition of the enzyme itself, which have each changed markedly over Earth history. Here we report the resurrection and genetic incorporation of a Precambrian-age, Form IB RuBisCO in a modern cyanobacterial host. The isotopic composition of biomass relative to $\mathrm{CO}_{2}\left(\varepsilon_{\mathrm{p}}\right)$ in ancestral and control strains were much greater when grown under Precambrian $\mathrm{CO}_{2}$ concentrations compared to modern ambient levels, but displaying values within a nominal envelope of modern-day RuBisCO IB enzyme variants. We infer that these isotopic differences derive indirectly from the decreased fitness of the AnclB strain, which includes diminished growth capacity and total cell RuBisCO activity. We argue that to answer the greatest questions of deeptime paleobiology, ancient biogeochemical signals should be reproduced in the laboratory through the synthesis of the geologic record with experimentally-derived constraints on underlying ancient molecular biology.
\end{abstract}

\section{Significance Statement}

The earliest geochemical indicators of microbes, and the enzymes that powered them, extend back almost 3.8 billion years on our planet. Paleobiologists often attempt to understand these indicators by assuming that the behaviors of modern microbes and enzymes are consistent (uniform) with those of their predecessors. This assumption seems uncomfortably at odds with the great variability of Earth's 
environment and its highly adaptive microbes. Here we examine whether a uniformitarian assumption for an enzyme thought to generate these indicators, $\mathrm{RuBisCO}$, can be corroborated by independently studying the history of changes recorded within RuBisCO's genetic sequences. We outline a new approach to paleobiology that informatively links molecule-level evolutionary changes with planet-level geochemical conditions in Earth's deep past.

\section{Introduction}

The history of life on Earth may be broadly subdivided into two, mutually exclusive macroevolutionary phases, the Phanerozoic and the Precambrian (1). The Phanerozoic ( 542 million years ago to present) may be characterized by physiological and anatomical innovations and their resultant effects on ecosystem expansion, trophic tiering, and sociality (2-4). Hard- and soft-anatomical preservation provides a rich template for reconstructing Phanerozoic adaptive trends, correlating them with geographical and climatological changes $(5,6)$, and for testing observed diversity trends against possible systematic effects of preservation bias (7-9). By contrast, the Precambrian (the $\sim 4$ billion years preceding the Phanerozoic) is primarily characterized by genetic and metabolic biomolecular innovations, traded amongst microscopic organisms of uncertain phylogenetic assignment $(10,11)$. The Precambrian record of evolutionary change appears to be cryptic and may have been comparatively static. This may be attributable to macroevolutionary dynamics that were distinctly non-Phanerozoic, or it may merely indicate a lack of direct paleontological and geological evidence of the specific timing and extent of intermediate biomolecular adaptive steps (1).

Comparative analyses of extant organisms have traditionally been the most informative means of interpreting the scant direct evidence of Precambrian life, but such analyses inevitably face pitfalls. A reasonable null hypothesis is that evolution is largely a uniformitarian process, such that rates or tempos may change but the underlying processes or modes of evolutionary change (as established through observations of the more comprehensive Phanerozoic record) are likely invariant in deep time (12). Uniformitarian assumptions of ancient biology inferred from extant or Phanerozoic phenotypes are often employed to make sense of the Precambrian record, including body plan function (13, 14), cladistic assignment (15-18), and isotope biosignature traces (19-23). However, more recent studies complicate the use of uniformitarian assumptions, namely indicating that modes of biological variation can actually vary through time (12). A major crux of the problem is that even the simplest modern organisms, as well as the macromolecules that compose them, differ from their ancient predecessors in having been shaped by the cumulative effects of billions of years of Earth-life co-evolution and ecosystem upheaval. For this reason, Precambrian functional or sequence comparisons may be of limited utility at organismal or biomolecular levels of adaptation, undercutting interpretations made possible by uniformitarian assumptions. Novel experimental approaches may help to distinguish inferred paleobiological phenotypes from characteristically modern adaptive overprints.

The interpretation of the Precambrian carbon isotope record, comprising the oldest signatures of life on Earth, may be aided by novel experimental constraints on ancient phenotypes. Interpretations of this record is conventionally subject to uniformitarian assumptions regarding ancient biogeochemistry (19, 24). The ${ }^{13} \mathrm{C} /{ }^{12} \mathrm{C}$ isotopic mean of preserved organic carbon $\left(\delta^{13} \mathrm{Corg}_{\mathrm{org}} \approx-25 \%\right.$ ) has remained notably static over geologic time $(19,21,24)$, and is leveraged as a general signature of ancient biological activity (25- 
27). Given its role in the Calvin-Benson-Bassham cycle-likely the predominant mode of carbon fixation for much of Earth history (19) - the majority of contextual information used to assess how carbon isotope biosignatures might have been generated over Earth's deep history comes from studies of the modern enzyme RuBisCO (Ribulose 1,5-Bisphosphate (RuBP) Carboxylase/Oxygenase, EC 4.1.1.39). RuBisCO catalyzes the uptake of inorganic $\mathrm{CO}_{2}$ from the environment and facilitates $\mathrm{CO}_{2}$ reduction and incorporation into organic biomass. The ${ }^{13} \mathrm{C} /{ }^{12} \mathrm{C}$ isotopic fractionation of modern Form I RuBisCO variants in photosynthetic organisms consistently measures $\sim-25 \%$ o (28-31), approximately the same isotopic difference observed between inorganic and organic carbon in the Precambrian rock record. The carbon isotope discrimination of RuBisCO has therefore been presumed to have remained constant over the history of life. Recent data, however, demonstrate that RuBisCO can produce significantly different carbon isotope signatures within organic matter in response to external factors, such as levels of atmospheric $\mathrm{CO}_{2}$ and/or $\mathrm{O}_{2}$ (32-35) or cellular carbon concentrating mechanisms, which affect the catalytic efficiency of RuBisCO (36-38). Internal factors may also affect fractionation, such as single-point mutations that can alter the interaction between RuBisCO and $\mathrm{CO}_{2}$ (39). Given the sensitivity of RuBisCO to both external and internal variables, it seems unlikely that ancestral forms under ancient environmental conditions generated the same isotope fractionation signal as descendent homologs in modern organisms. An experimental assessment that combines the phylogenetic history of RuBisCO with the study of intra- and extracellular conditions may provide a more insightful basis for comparing extant and Precambrian carbon isotope fractionation patterns.

The Form I clade of the RuBisCO phylogeny (and its macroevolutionary tractability afforded through green plant, algal and cyanobacterial fossil lineages) makes it an exemplary paleomolecular system for assessing uniformitarian assumptions applied to Precambrian biosignatures. Here, we establish an experimental system for the reconstruction of ancestral biomolecules with which to interpret evidence of Precambrian biological activity. Specifically, we report the resurrection and genetic incorporation of a phylogenetically reconstructed, ancient Form IB RuBisCO variant in a modern strain of cyanobacteria, Synechococcus elongatus PCC 7942 (thereafter S. elongatus) $(40,41)$. We compared expression and activity levels of RuBisCO variants and the resulting changes in the growth of $S$. elongatus and isotope fractionation under ambient air as well as a $\mathrm{CO}_{2}$ concentration that reflects Precambrian conditions.

\section{Results}

Construction of a S. elongatus strain harboring ancestral RuBisCO. To experimentally investigate the generation of carbon isotope biosignatures in deep time, we designed a paleomolecular system to engineer computationally inferred, ancestral RuBisCO enzymes in extant cyanobacteria. We previously reconstructed a comprehensive phylogenetic history of RuBisCO and inferred maximum-likelihood ancestral RuBisCO large-subunit ( $\mathrm{RbcL}$ ) protein sequences (42) (Fig. 1A). For this study, we selected the ancestor of the Form IB RuBisCO clade (cyanobacteria, green algae, and land plants) for laboratory resurrection, designated "AnclB." Chlorophyte and land plant RuBisCO homologs are nested among cyanobacterial sequences within the Form IB clade. The Form IB topology therefore recapitulates a primary plastid endosymbiotic history from cyanobacterial to Chlorophyte ancestors (43-45) and constrains the minimum age of ancestral Form IB to older than the Archaeplastida. As a conservative estimate, AnclB is thus likely older than $\sim 1 \mathrm{Ga}$ (the age of the oldest well-characterized, crown-group red and green algal fossils $(16,46)$ ) and younger than maximum age estimates of cyanobacteria ( $3 \mathrm{Ga}$, as 
constrained by oxidized sediments potentially indicating the early presence of oxygenic photosynthesis $(47,48))$.

The ancestral AnclB and S. elongatus native RbcL proteins differ at 37 sites and share $92 \%$ amino acid identity (Fig. 2). This site variation is evenly spread across the length of the protein, except for a highly conserved region between approximately site 170 to 285 (site numbering here and hereafter based on aligned WT S. elongatus RbcL; Fig. 2A) that constitutes a portion of the catalytic $\mathrm{C}$-terminal domain and is proximal to the L-L interface and active site. Critical residues for carboxylase activity, including the Lys198 site that binds $\mathrm{CO}_{2}$, are conserved in AnclB. Homology modeling of AnclB using the S. elongatus RbcL template (PDB: 1RBL (49)) indicates high structural conservation without predicted disruption to secondary structure (Fig. 2B). The nucleotide sequence for the reconstructed AnclB RbcL protein was codon-optimized for S. elongatus and cloned within a copy of the rbc operon into pSyn02 (50) for insertion into the S. elongatus chromosomal neutral site 2 (NS2). The native $r b c$ operon was subsequently deleted to create the AnclB strain. In addition, we generated the control strain Syn01 harboring WT rbcL at NS2 (see Materials and Methods for full genome strategy). Thus, the AnclB and Syn01 strains carry a single ectopic copy of the rbc operon at NS2 and only differ in the coding sequence of the large RuBisCO subunit (Table 1).

Ancestral RuBisCO complements photoautotrophic growth of extant S. elongatus. We cultured wildtype (WT) and engineered (AncIB and Syn01) strains of S. elongatus in both ambient air and $2 \% \mathrm{CO}_{2}$ to evaluate the physiological impact of ancestral RuBisCO under estimated Precambrian $\mathrm{CO}_{2}$ concentrations (51) (Fig. 3A). The AnclB strain was capable of photoautotrophic growth in both ambient air and $2 \% \mathrm{CO}_{2}$. Maximum growth rates for all strains were relatively comparable under each atmospheric condition (averaging doubling times of $\sim 15$ to 20 hours), and generally increased under $2 \% \mathrm{CO}_{2}$ relative to air ( $p<$ 0.001 ; Table 2$)$. The AnclB strain exhibited a significantly diminished maximum cell density $\left(\mathrm{OD}_{750} \approx 5\right)$ relative to both WT and Syn02 strains $\left(\mathrm{OD}_{750} \approx 8 ; p<0.001\right)$. No significant difference between WT and Syn01 growth rate or maximum cell density was observed under ambient air or $2 \% \mathrm{CO}_{2}$. In addition, a moderate increase in the midpoint time for the AnclB strain was observed under air, indicating lag in growth $(p<0.01)$. These growth parameters taken together suggest decreased fitness of the AnclB strain relative to WT and Syn01.

AnclB RuBisCO protein produced a more modest impact on the oxygen evolution of $S$. elongatus compared to that on growth parameters. Cell suspensions were briefly incubated in the dark and subsequently exposed to saturated light in an electrode chamber to detect evolution of molecular oxygen (normalized to chlorophyll $a$ concentration (52)). For cells sampled from cultures grown in air, there was no statistical difference detected between any of the WT, Syn01, or AnclB strains (Fig. 3B). We did find a modest but significant decrease in photosynthetic activity for AnclB relative to WT for cells cultured in $2 \% \mathrm{CO}_{2}$, generating $\sim 200$ and $\sim 320 \mathrm{nmol} \mathrm{O}{ }_{2} \cdot \mathrm{h}^{-1} \cdot \mathrm{\mu g}^{-1}$ chlorophyll $a$, respectively. However, a slower $\mathrm{O}_{2}$ evolution rate was also observed for Syn01 at $2 \% \mathrm{CO}_{2}$.

Ancestral RuBisCO is overexpressed and less catalytically active relative to WT. We assessed the impact of ancestral RuBisCO on gene expression at both the transcript and protein levels. S. elongatus rbcL transcript was measured by quantitative reverse-transcription PCR (RT-qPCR) and normalized to that of the secA reference gene (53). For strains cultured in ambient air, we found that the AnclB strain produced 
a 29-fold increase in $r b c L$ transcript relative to WT or the control strain Syn01 $(p<0.001$; Fig. 4A). The magnitude of AnclB $r b c L$ overexpression was lower in $2 \% \mathrm{CO}_{2}$, with a $\sim 4$ and $\sim 2$-fold increase observed relative to WT and the control strain, respectively $(p<0.001)$.

$\mathrm{RbcL}$ protein was quantified for all S. elongatus strains by immunodetection using rabbit anti-RbcL antibody. We found that the amount of RbcL protein was also increased in the AnclB strain by $\sim 3-$ fold ( $p$ $<0.05)$ and $\sim 5$-fold $(p<0.001)$ relative to WT or Syn01 in air and $2 \% \mathrm{CO}_{2}$, respectively (Fig. 4B). No difference in RbcL quantity was detected between WT and Syn01 strains at either atmospheric condition. Finally, we confirmed assembly of the hexadecameric $\mathrm{L}_{8} \mathrm{~S}_{8}$ RuBisCO complex in the AnclB strain by native PAGE and detection by anti-RbcL antibody (Fig. S1).

The total carboxylase activity of $S$. elongatus harboring ancestral RuBisCO was measured from crude cell lysates. Activity was assessed by an in vitro spectrophotometric coupled-enzyme assay that measures NADH oxidation and is reported as the RuBP consumption rate normalized to total soluble protein content (54). For two sets of assays using either $2.5 \mathrm{mM}$ or $5 \mathrm{mM} \mathrm{HCO}_{3}{ }^{-}$, AnclB lysate generated less than half the carboxylase activity of WT lysate $(p<0.05)$ (Fig. 4C).

\section{S. elongatus harboring ancestral RuBisCO produces greater carbon isotopic fractionation than wild-} type. We measured the carbon isotope discrimination of $S$. elongatus strains cultured in ambient air and $2 \% \mathrm{CO}_{2}$ to evaluate how the fractionation behavior of ancestral RuBisCO might influence the interpretation of ancient isotopic biosignatures preserved in the geologic record. The ${ }^{13} \mathrm{C} /{ }^{12} \mathrm{C}$ carbon isotope composition of $S$. elongatus was measured for biomass $\left(\delta^{13} \mathrm{C}_{\text {biomass }}\right)$ as well as dissolved inorganic carbon (DIC; $\delta^{13} C_{D I C}$ ) in the growth medium (Table S1). We calculated the carbon isotope fractionation associated with photosynthetic $\mathrm{CO}_{2}$ fixation $\left(\varepsilon_{\mathrm{p}}\right)$ following Freeman and Hayes (33) after estimating $\delta^{13} \mathrm{C}_{\mathrm{CO} 2}$ from measured $\delta^{13} C_{D I C}(55,56)$ (see Materials and Methods).

Overall, $\varepsilon_{\mathrm{p}}$ values were greater for $S$. elongatus strains cultured in $2 \% \mathrm{CO}_{2}$ compared to ambient air. At $2 \%$ $\mathrm{CO}_{2}, \varepsilon_{\mathrm{p}}$ ranged between $21 \%$ ond $26 \%$ o compared to only $8 \%$ and $14 \%$ in air. We found that $S$. elongatus engineered with AnclB RbcL had an $\varepsilon_{\mathrm{p}} \sim 5 \%$ greater than both WT and Syn01 when cultured in air $(p<$ 0.001 ) and $\sim 2 \%$ to $4 \%$ greater than WT and Syn01 when cultured at $2 \% \mathrm{CO}_{2}(p<0.01)$ (Fig. $\left.1 \mathrm{C}\right)$, though these differences in $\varepsilon_{\mathrm{p}}$ appear driven by the inorganic carbon pool composition rather than biomass (Table S1). A substantially smaller increase in $\varepsilon_{\mathrm{p}}(\sim 1 \% ; p<0.001)$ was observed for Syn01 relative to WT under ambient air. Conversely, under $2 \% \mathrm{CO}_{2}$, Syn01 $\varepsilon_{\mathrm{p}}$ was decreased by $\sim 2 \%$ o $(p<0.001)$ relative to WT.

\section{Discussion}

Form IB ancestral RuBisCO, when engineered into an extant strain of S. elongatus, decreased both the organismal growth capacity and the total cell RuBisCO activity. The genetic engineering strategy for insertion of the AnclB rbcL sequence in the cyanobacterial genome cannot solely account for these physiological differences since differences between the WT and Syn01 control strains were insignificant for most measured properties, or not comparable in magnitude to differences between the WT and AnclB strains. Rather, the observed differences for the AnclB strain indicate that the resultant phenotype is likely attributable to the functionality of the ancestral enzyme itself. The unique phenotype of the AnclB strain could be a direct result of the ancestral RbcL subunit or due to impediments to the assembly and activation 
of a hexadecamer RuBisCO complex containing both the ancestral RbcL and modern RbcS subunits. Another possibility is hampered integration of ancestral $\mathrm{RbcL}$ given a modern suite of associated proteins required for RuBisCO folding and assembly (57). Further, while overexpression of the ancestral RbcL occurred at the level of transcription and translation, the ancestral strain appears to have comparable levels of assembled hexadecamer RuBisCO, suggesting lower rates of RuBisCO assembly (or faster degradation). Even lower rates of measured total carboxylase activity suggest that the AnclB has decreased efficacy, which could be directly representing ancestral RuBisCO kinetics as well as the challenges associated with hybrid enzyme activation and activity.

Overexpression of the amount of ancestral RuBisCO shown by RT-qPCR and immunodetection assays is a common physiological response to decreased enzymatic efficacy throughout the cell (e.g., $(58,59))$. However, expression compensation is insufficient to fully restore the extant WT phenotype, as indicated by the reduced fitness (i.e., decreased maximum cell density, oxygen evolution, and total carboxylase activity) of the ancestral strain harboring the ancestral RuBisCO compared to WT and Syn01.

There are few in vitro measurements of the kinetic isotope effect of Form IB RuBisCO in modern-day organisms, but those available range from $\sim 22 \%$ o to $28 \%$ o for cyanobacteria and $C_{3}$ plants, respectively (28-31). The $\sim 26 \%$ o $\varepsilon_{\mathrm{p}}$ of AnclB strain biomass grown under $2 \% \mathrm{CO}_{2}$ suggests that the ancestral RuBisCO also fractionates within this range. It has been theorized that RuBisCO kinetics have adapted in response to $\mathrm{CO}_{2}$ availability, either due to increased environmental $\mathrm{CO}_{2}(36)$ or the emergence of $\mathrm{CCMs}$ (e.g., $\mathrm{C}_{4}$ photosynthesis in plants (60)). Considering the positive relationship between enzymatic fractionation and RuBisCO's specificity to $\mathrm{CO}_{2}$ (36), reconstructing ancient RuBisCO kinetic isotope effect could provide insights into the co-evolution of atmospheric concentrations of $\mathrm{CO}_{2}$ and $\mathrm{O}_{2}$ and carbon fixation strategies during the Precambrian, in particular the emergence of carbon concentrating mechanisms (CCMs) (34, 61-63). This is relevant as precise estimates of the magnitude of atmospheric $\mathrm{CO}_{2}$ elevation during the Precambrian relative to the present, as well as the emergence and effectiveness of Precambrian CCMs, are unknown.

We did observe statistically significant differences in $\varepsilon_{\mathrm{p}}$ of the ancestral strain compared to WT $S$. elongatus under both ambient air and $2 \% \mathrm{CO}_{2}$ atmospheric conditions. However, upon inspection it appears that the diminished activity of the AnclB strain is influencing the composition of the DIC pool (both $\delta^{13} \mathrm{C}$ and concentration) in our cultures, and it is in fact the differences in DIC composition driving the calculated differences in $\varepsilon_{\mathrm{p}}$. Though strains were harvested at similar cell densities, small differences in cell concentrations at high densities can strongly influence carbonate chemistry of the media (64). The lower $\mathrm{CO}_{2}$ availability in the air treatment is more sensitive to cellular influence, resulting in a larger difference in $\varepsilon_{\mathrm{p}}$ compared to the $2 \% \mathrm{CO}_{2}$ treatment. These differences in DIC are unlikely to be due to experimental setup (e.g., variations in $\mathrm{CO}_{2}$ bubbling), as biological replicates showed similar values. Therefore, the differences in fractionation reported here are likely implicated indirectly with the less efficient AnclB ancestral enzyme. Further comparative biomolecular characterization of AnclB and WT S. elongatus $\mathrm{RbcL}$ forms is needed to determine the degree to which enzymatic inefficiencies are contributing directly to the AnclB strain phenotype. 
biosignatures. There are, however, several potentially important contextual caveats. The most obvious is that the isotopic fractionation values of all strains (WT, Syn01, and AnclB) are increased under simulated Precambrian conditions with elevated $\mathrm{CO}_{2}$. The Form IB ancestor represents predecessors that are at least 1 billion years old, but it is also genetically and functionally still likely to be very different from the putative 'root' or common ancestor of all RuBisCO variants that emerged much earlier. Reconstruction of older ancestors may further expand this maximal envelope of RuBisCO-generated carbon fractionation, or it may indicate that the extant maximal envelope is pervasive (and perhaps characteristic) across all functional variants of RuBisCO.

Another important caveat lies in the observation that, whereas all strains produce increased isotopic fractionation under elevated $\mathrm{CO}_{2}$, the comparative difference between ancestral AnclB and WT RbcL fractionation is relatively muted under $2 \% \mathrm{CO}_{2}$ relative to ambient air. One possibility is that elevated $\mathrm{CO}_{2}$ brings the intrinsic fractionation properties of RuBisCO into relief $(35,65-67)$, at least compared to fractionation effects deriving from the overlying organismal physiology. By contrast, in present-day conditions, RuBisCO-mediated fractionation processes may be more significantly overprinted by physical factors that can affect RuBisCO catalytic efficiency, including cellular diffusion of $\mathrm{O}_{2} / \mathrm{CO}_{2}$ or other factors such as the presence of carbon concentration mechanisms.

There are many fundamental attributes of extant and ancestral metabolism for which the systemic effects on biosignature production have yet to be characterized. Disentangling these effects is critical for interpretation of the oldest biogeochemical record. A host cyanobacterium S. elongatus engineered with a Form IB RbcL ancestor confirms that organism- and enzyme-level effects on biosignature production are not always synonymous but differ in nuanced ways. These differences are contingent upon changes to internal (cellular, physiological) and external (environmental) conditions that have demonstrably varied over Earth's long history. Cyanobacteria, with well-characterized genetic and morphological features (40, $41,61-63)$ and a tractable paleobiological history $(18,68)$, are ideal hosts for investigating a range of early Precambrian metabolic processes (68-70).

Discernible trends (or steadfast consistencies) in metabolic outputs over macroevolutionary timescales can lead to foundational uniformitarian approaches to deep time molecular paleobiology. The available rock record becomes vanishingly sparse with greater age, but it is arguably well-sampled across key globalscale and biotically relevant isotopic systems at least through the early Archaean. Greater geologic sampling will therefore likely generate diminishing returns for shedding new light on deep time paleobiological trends. Innovative approaches that can chart a comprehensive envelope of biomolecular variability over time are a promising new means of reconciling coarse geochemical data with the nuance and complexity of ancient biological activity.

The engineering of ancient-modern hybrid organisms and their characterization can be used to complement the existing array of fossil remains, biogeochemical signatures, and modern organismal and molecular proxies to assess and contextualize plausible ranges of Precambrian carbon isotope biosignature production. Hybrid organisms may be particularly useful to disentangle the regulatory, physiological, and inter- and intramolecular factors that have impacted isotope fractionation, none of 
for when interpreting bulk fractionation signals, even if only to elucidate the evolutionary molecular underpinnings of uniformitarian phenomena over geologic time.

\section{Conclusions}

After engineering a cyanobacterium with an ancient RuBisCO large protein subunit and cultivating it under conditions that mimic those prevailing through much of the Precambrian, we found the resultant carbon isotope fractionation to be within the range of organisms utilizing modern Form IB RuBisCO. The underlying biomolecular and organismal adjustments made by the cell to accommodate the ancestral gene were tracked, and we conclude that the small fractionation differences observed are likely attributable indirectly to decreased fitness of the AnclB strain, which influenced the inorganic carbonate chemistry of the media. The consistency of isotopic signatures generated by this strain indicates that uniformitarian assumptions based on the range of phenotypes of modern RuBisCO variants may apply for Precambrian environmental conditions, but that further study is warranted to discern organism- and enzyme-level trends in carbon isotope fractionation that may extend deeper into the early Precambrian.

\section{Materials and Methods}

Inference of ancestral AnclB RbcL protein sequence. A RuBisCO RbcL phylogeny was reconstructed as previously described (42). Briefly, RbcL orthologs were identified from the NCBI protein database by BLAST (sequence dataset and the tree can be found at https://github.com/kacarlab/rubisco). Phylogenetic analysis was performed by Phylobot (71), a web portal that integrates alignment, phylogenetic reconstruction by RAxML (72), and ancestral sequence inference by PAML (73). A maximum likelihood phylogeny was built using a MSAProbs alignment (74) and the best-fit PROTCATWAG model $(75,76)$, determined by the Akaike information criterion (77). Ancestral states were reconstructed at each amino acid site for all phylogenetic nodes, and gap characters were inferred according to Fitch's parsimony (78).

Cyanobacterial growth and maintenance. S. elongatus PCC 7942 strains were cultured in BG-11 medium (79) as liquid cultures or on agar plates $\left(1.5 \%(\mathrm{w} / \mathrm{v})\right.$ agar and $\left.1 \mathrm{mM} \mathrm{Na}_{2} \mathrm{~S}_{2} \mathrm{O}_{3} \cdot 5 \mathrm{H}_{2} \mathrm{O}\right)$. Liquid cultures were grown at $30^{\circ} \mathrm{C}$, continuous shaking at $120 \mathrm{rpm}$, sparged with ambient air or $2 \% \mathrm{CO}_{2}$, and with $115 \mu \mathrm{mol}$ photon $\cdot \mathrm{m}^{-2} \cdot \mathrm{s}^{-1}$ (with the exception of cultures used to prepare samples for $\mathrm{O}_{2}$ evolution, which were grown with $80 \mu \mathrm{mol}$ photon $\cdot \mathrm{m}^{-2} \cdot \mathrm{s}^{-1}$ ). The $2 \% \mathrm{CO}_{2}$ gas mix was controlled by an environment chamber (Percival, Cat. No. I36LLVLC8) with a $\mathrm{CO}_{2}$ tank input. For recombinant strains, liquid and solid media were supplemented with appropriate antibiotics: $2 \mu \mathrm{g} \cdot \mathrm{ml}^{-1}$ Spectinomycin (Sp) plus $2 \mu \mathrm{g} \cdot \mathrm{ml}^{-1}$ Streptomycin $(\mathrm{Sm}), 5 \mu \mathrm{g} \cdot \mathrm{ml}^{-1}$ Kanamycin $(\mathrm{Km})$. Cyanobacterial growth was measured at an optical density of $750 \mathrm{~nm}$ $\left(O D_{750}\right)$ and growth parameters were estimated using the Growthcurver package for $\mathrm{R}(80)$ (Growthcurver analysis script can be found at https://github.com/kacarlab/rubisco). Cultures were sampled at the middle exponential growth phase, i.e., at an $\mathrm{OD}_{750}$ of $\sim 2.5$ (AnclB) or $\sim 4.5$ (WT and Syn01) for all subsequent experiments.

Genetic engineering of cyanobacteria. Recombinant strains of $S$. elongatus were constructed by natural transformation using standard protocols (81) with minor modifications (50). The plasmids and strains used in this study are listed in Table 1. The construction of S. elongatus Syn01, carrying a single ectopic copy of the $r b c$ operon at NS2, as well as the plasmids pSyn01 and pSyn02 used to construct strain Syn01, were described previously (50). The construction of strain AnclB was performed similarly to Syn01. Briefly, 
pSyn03, which carries the AnclB nucleotide sequence within the entire $r b c$ operon (including flanking sequences and homologous regions for recombination at neutral site 2 (NS2) of the S. elongatus chromosome), was transformed in S. elongatus. Transformation of WT S. elongatus with pSyn03 generated strain Syn03 carrying a second copy of the rbc operon at NS2. Strain Syn03 was subsequently transformed with pSyn01 to replace the native $r b c$ operon with a spectinomycin/streptomycin resistance gene as described previously (50), producing strain AnclB. Transformants of Syn03 and AnclB were screened for complete segregation by colony PCR using primers F06, R06, F07, and R07 (Fig. S2; Table S2) and the strain sequences at the deletion and insertion sites were further verified by Sanger sequencing using the primers R07, F08, R08, F15, and F16 (Table S2). To construct plasmid pSyn03, pSyn02 excluding the $r b c L$ coding sequence was PCR-amplified and linearized using primers F13/R13 and assembled with the AnclB RbcL coding sequence codon-optimized for $S$. elongatus and synthesized by Twist Bioscience. Both DNA fragments were assembled using the GeneArt ${ }^{\mathrm{TM}}$ Seamless Cloning and Assembly Kit (Invitrogen, Cat. No. A13288).

Analysis of $r b c L$ expression by RT-qPCR. Cells were pelleted by centrifugation and resuspended in TE buffer (10 mM Tris, pH 8.0, 1 mM EDTA). Total RNA was extracted using the RNeasy ${ }^{\circledR}$ Protect Bacteria Mini Kit (QIAGEN, Cat. No. 74524). DNase I-treated RNA was then used in reverse transcription (RT) performed with the SuperScript ${ }^{\mathrm{TM}}$ IV First-Strand Synthesis System (Invitrogen, Cat. No. 18091050). F09/R09, F11/R11, F14/R14 pairs of GPCR primers (Table S2) were designed with Primer3Plus (http://www.bioinformatics.nl/cgi-bin/primer3plus/primer3plus.cgi). The quality of cDNA and primer specificity was assessed by PCR using CDNA templates (RT positive reactions) and RT negative controls. qPCR was performed by the real-time thermal cycler qTOWER ${ }^{3} \mathrm{G}$ (Analytik Jena AG) using qPCRsoft software. The relative expression of native and AncIB rbcL was calculated as the average fold change normalized to the secA reference gene (53) using the delta-delta $\mathrm{Ct}$ method. The experiment was carried out using three biological replicates and three technical replicates.

Immunodetection of RbcL protein. Cells were pelleted by centrifugation and resuspended in $95^{\circ} \mathrm{C} \mathrm{TE}$ buffer supplemented with $1 \%(\mathrm{w} / \mathrm{v}) \mathrm{SDS}$ and incubated at $95^{\circ} \mathrm{C}$ for $10 \mathrm{~min}$. The mixture was sonicated and centrifuged to remove cell debris. Total protein concentration in the crude cell lysates was measured using the Pierce ${ }^{\mathrm{TM}}$ BCA Protein Assay Kit (Thermo Scientific, Cat. No. 23225). Lysates containing $5 \mu \mathrm{g}$ of total protein in Laemmli sample buffer were loaded onto a $6 \%(\mathrm{v} / \mathrm{v})$ polyacrylamide stacking gel. Proteins were electrophoresed in a $12 \%$ polyacrylamide resolving gel and blotted onto a nitrocellulose membrane. Detection of $\mathrm{RbcL}$ and total protein load was performed as previously described (50). The densitometric analysis of RbcL signal intensity, normalized to total protein load, was performed with Quantity One ${ }^{\circledR}$ software (Bio-Rad) for three to six biological replicates.

Confirmation of RuBisCO assembly. Assembly of the RuBisCO large and small subunits into a hexadecameric complex in each strain was evaluated by native gel electrophoresis and immunodetection, as previously described (50). Immunodetection of the RuBisCO complex was performed for three biological replicates with the same primary and secondary antibodies that were used to detect RbcL, as described above.

Catalytic activity of RuBisCO. The activity of RuBisCO in cyanobacterial lysates was measured using a spectrophotometric coupled-enzyme assay that links this activity with the rate of NADH oxidation (82). Cell lysis and the activity assay were carried out as previously described (50) with either $2.5 \mathrm{mM}$ or $5 \mathrm{mM}$ $\mathrm{NaHCO}_{3}$. After $20 \mathrm{~min}$ at $25^{\circ} \mathrm{C}$ for activation of Rubisco, the reaction was initialized with the addition of ribulose 1,5-bisphosphate (RuBP) $(0.5 \mathrm{mM})$ and the absorbance at $340 \mathrm{~nm}$ was recorded using a Synergy 
$\mathrm{H} 1$ plate reader (BioTek). RuBisCO activity was reported as the RuBP consumption rate normalized to total soluble protein content. The assay was performed for three biological replicates.

Photosynthetic oxygen evolution rate. S. elongatus strain photosynthetic activity was assayed using a Clark-type oxygen electrode chamber to measure the level of molecular oxygen produced in cyanobacterial cultures. Cells were pelleted and resuspended in fresh BG-11 to an $\mathrm{OD}_{750}$ of $\sim 1$ following De Porcelinis (83). Concentration of chlorophyll $a$ (for normalization) was measured following the protocol by Zavrel et al. (84). The remaining suspension was incubated in the dark for 20 min with gentle agitation. Samples from each suspension were analyzed in an oxygen electrode chamber under saturated light, using the Oxygraph+System (Hansatech Instruments) equipped with the OxyTrace+ software. Oxygen evolution rate was monitored for $10 \mathrm{~min}$ and expressed as nanomoles of molecular oxygen evolved per hour per microgram of chlorophyll $a$. The assay was performed for three biological replicates.

408

Carbon isotope fractionation in bulk cyanobacterial biomass. Cells were pelleted by centrifugation and washed in $10 \mathrm{~mL}$ of $10 \mathrm{mM} \mathrm{NaCl}\left(\mathrm{OD}_{750}\right.$ for Syn-1 4.5, OD 750 for AnclB $\left.\sim 2.5\right)$. Pellets were then dried at $50^{\circ} \mathrm{C}$. In parallel, the supernatant from centrifuged culture samples was sterilized through $0.2 \mu \mathrm{m}$ filtration for DIC isotopic analysis of growth media. Sterilized media was transferred to Exetainer vials leaving no headspace and stored at $4^{\circ} \mathrm{C}$ until analysis. Isotopic analysis was performed for three biological replicates. The carbon isotope composition of bulk biomass $\left(\delta^{13} C_{\text {biomass }}\right)$ and DIC $\left(\delta^{13} C_{D I C}\right)$ was determined at the UC Davis Stable Isotope Facility. $\delta^{13} C_{\text {biomass }}$ was analyzed using a PDZ Europa ANCA-GSL elemental analyzer interfaced to a PDZ Europa 20-20 isotope ratio mass spectrometer (Sercon Ltd.). DIC samples were analyzed by gas evolution and composition was measured by a GasBench II system interfaced to a Delta $\checkmark$ Plus IRMS (Thermo Scientific). The carbon isotopic composition values were reported relative to the Vienna PeeDee Belemnite standard (V-PDB):

The isotopic composition of dissolved molecular $\mathrm{CO}_{2}\left(\delta^{13} \mathrm{C}_{\mathrm{CO} 2}\right)$ was estimated from $\delta^{13} \mathrm{C}_{\mathrm{DIC}}$ following Rau et al. (55) and Mook et al. (56):

$$
\delta{ }^{13} C_{\text {sample }}=\left(\frac{{ }^{13} C /{ }^{12} C_{\text {sample }}}{{ }^{13} C /{ }^{12} C_{V-P D B}}-1\right) \times 1000
$$

The carbon isotope fractionation associated with photosynthetic $\mathrm{CO}_{2}$ fixation $\left(\varepsilon_{\mathrm{p}}\right)$ was calculated relative to $\delta^{13} C_{\mathrm{CO} 2}$ in the post-culture medium according to Freeman and Hayes (1992):

$$
\delta^{13} C_{C_{2}}=\delta^{13} C_{D I C}+23.644-\frac{9701.5}{T_{K}}
$$
standard deviation $(1 \sigma)$ values of at least three biological replicates. For comparisons of two groups, statistical significance was analyzed by an unpaired, two-tailed $t$-test assuming equal variance. For comparisons of three or more groups, significance was analyzed by one-way ANOVA and a post-hoc Tukey HSD test. 


\section{Acknowledgements}

We sincerely thank Emily Peñaherrera, Jenan Kharbush, Ryan Ward, Sky Dominguez, and the University of California-Davis Stable Isotope Facility for assistance. This work was supported by the National Aeronautics and Space Administration Early Career Faculty (ECF) Award No. 80NSSC19K1617 (BK), the National Science Foundation Emerging Frontiers Program Award No. 1724090 (BK), National Aeronautics and Space Administration Postdoctoral Fellowship (AKG), Simons Foundation Early Career Award No. 561645 (JNY and ML), and National Institute of General Medical Sciences of the National Institutes of Health award number R01GM118815 (AT, to James W. Golden at the University of California-San Diego).

\section{References}

1. N. J. Butterfield, Macroevolution and Macroecology through Deep Time. Palaeontology 50, 4155 (2007). https://doi.org/10.1111/j.1475-4983.2006.00613.x

2. B. Hannisdal, S. E. Peters, Phanerozoic Earth System Evolution and Marine Biodiversity. Science 334, 1121-1124 (2011). https://doi.org/10.1126/science.1210695

3. R. K. Bambach, "Classes and Adaptive Variety: The Ecology of Diversification in Marine Faunas Through the Phanerozoic" in Phanerozoic Diversity Patterns, J. W. Valentine, Ed. (Princeton University Press, 1986), pp. 191-254.

4. D. J. Bottjer, W. I. Ausich, Phanerozoic development of tiering in soft substrata suspensionfeeding communities. Paleobiology 12, 400-420 (2016). https://doi.org/10.1017/s0094837300003134

5. J. J. Sepkoski, Biodiversity: Past, Present, and Future. J Paleontol 71, 533-539 (2015). https://doi.org/10.1017/s0022336000040026

6. G. J. Vermeij, Adaptation, Versatility, and Evolution. Syst Zool 22 (1973). https://doi.org/10.2307/2412953

7. A. J. W. Hendy, "Taphonomic Overprints on Phanerozoic Trends in Biodiversity: Lithification and Other Secular Megabiases" in Taphonomy, P. A. Allison, D. J. Bottjer, Eds. (Springer, Dordrecht, 2010), pp. 19-77.

8. S. E. Peters, Geologic constraints on the macroevolutionary history of marine animals. Proc Natl Acad Sci USA 102, 12326-12331 (2005). https://doi.org/10.1073/pnas.0502616102

9. S. E. Peters, M. Foote, Biodiversity in the Phanerozoic: a reinterpretation. Paleobiology 27, 583601 (2016). https://doi.org/10.1666/0094-8373(2001)027<0583:Bitpar>2.0.Co;2

10. A. H. Knoll, Paleobiological Perspectives on Early Microbial Evolution. Cold Spring Harbor Perspectives in Biology 7, a018093 (2015). https://doi.org/10.1101/cshperspect.a018093

11. J. W. Schopf, Disparate rates, differing fates: tempo and mode of evolution changed from the Precambrian to the Phanerozoic. Proc Natl Acad Sci USA 91, 6735-6742 (1994). https://doi.org/10.1073/pnas.91.15.6735

12. D. H. Erwin, Evolutionary uniformitarianism. Dev Biol 357, 27-34 (2011). https://doi.org/10.1016/i.ydbio.2011.01.020

13. Z. R. Adam, M. L. Skidmore, D. W. Mogk, N. J. Butterfield, A Laurentian record of the earliest fossil eukaryotes. Geology 45, 387-390 (2017). https://doi.org/10.1130/g38749.1

14. Z. Yin, M. Zhu, D. J. Bottjer, F. Zhao, P. Tafforeau, Meroblastic cleavage identifies some Ediacaran Doushantuo (China) embryo-like fossils as metazoans. Geology 44, 735-738 (2016). https://doi.org/10.1130/g38262.1 
15. N. J. Butterfield, Bangiomorpha pubescens n. gen., n. sp.: implications for the evolution of sex, multicellularity, and the Mesoproterozoic/Neoproterozoic radiation of eukaryotes. Paleobiology 26, 386-404 (2000). https://doi.org/10.1666/0094-8373(2000)026<0386:Bpngns >2.0.Co;2

16. Q. Tang, K. Pang, X. Yuan, S. Xiao, A one-billion-year-old multicellular chlorophyte. Nat Ecol Evol 4, 543-549 (2020). https://doi.org/10.1038/s41559-020-1122-9

17. S. Golubic, L. Seong-Joo, Early cyanobacterial fossil record: preservation, palaeoenvironments and identification. Eur J Phycol 34, 339-348 (1999). https://doi.org/10.1080/09670269910001736402

18. J. W. Schopf, The paleobiological record of photosynthesis. Photosynth Res 107, 87-101 (2011). https://doi.org/10.1007/s11120-010-9577-1

19. M. Schidlowski, Carbon isotopes as biogeochemical recorders of life over 3.8 Ga of Earth history: evolution of a concept. Precambrian Res 106, 117-134 (2001). https://doi.org/Doi 10.1016/S0301-9268(00)00128-5

20. B. L. Beard, Iron Isotope Biosignatures. Science 285, 1889-1892 (1999). https://doi.org/10.1126/science.285.5435.1889

21. A. K. Garcia, C. M. Cavanaugh, B. Kacar, The curious consistency of carbon biosignatures over billions of years of Earth-life coevolution. ISMEJ (2021). https://doi.org/10.1038/s41396-021$\underline{00971-5}$

22. A. D. Anbar, O. Rouxel, Metal Stable Isotopes in Paleoceanography. Annu Rev Earth PI Sc 35, 717-746 (2007). https://doi.org/10.1146/annurev.earth.34.031405.125029

23. J. W. Schopf et al., Sulfur-cycling fossil bacteria from the 1.8-Ga Duck Creek Formation provide promising evidence of evolution's null hypothesis. Proc Natl Acad Sci USA 112, 2087-2092 (2015). https://doi.org/10.1073/pnas.1419241112

24. J. Krissansen-Totton, R. Buick, D. C. Catling, A statistical analysis of the carbon isotope record from the Archean to Phanerozoic and implications for the rise of oxygen. Am J Sci 315, 275-316 (2015). https://doi.org/10.2475/04.2015.01

25. M. Schidlowski, A 3,800-Million-Year Isotopic Record of Life from Carbon in Sedimentary-Rocks. Nature 333, 313-318 (1988). https://doi.org/10.1038/333313a0

26. J. W. Schopf, K. Kitajima, M. J. Spicuzza, A. B. Kudryavtsev, J. W. Valley, SIMS analyses of the oldest known assemblage of microfossils document their taxon-correlated carbon isotope compositions. Proc Natl Acad Sci USA 115, 53-58 (2018). https://doi.org/10.1073/pnas.1718063115

27. E. A. Bell, P. Boehnke, T. M. Harrison, W. L. Mao, Potentially biogenic carbon preserved in a 4.1 billion-year-old zircon. Proc Natl Acad Sci USA 112, 14518-14521 (2015). https://doi.org/10.1073/pnas.1517557112

28. K. M. Scott et al., Kinetic isotope effect and biochemical characterization of form IA RubisCO from the marine cyanobacterium Prochlorococcus marinus MIT9313. Limnol Oceanogr 52, 21992204 (2007).

29. R. D. Guy, M. L. Fogel, J. A. Berry, Photosynthetic fractionation of the stable isotopes of oxygen and carbon. Plant Physiol 101, 37-47 (1993). https://doi.org/10.1104/pp.101.1.37

30. S. von Caemmerer, Y. Tazoe, J. R. Evans, S. M. Whitney, Exploiting transplastomically modified Rubisco to rapidly measure natural diversity in its carbon isotope discrimination using tuneable diode laser spectroscopy. J Exp Bot 65, 3759-3767 (2014). https://doi.org/10.1093/jxb/eru036

31. C. A. Roeske, M. H. O'Leary, Carbon isotope effects on the enzyme-catalysed carboxylation of ribulose bisphosphate. Biochemistry 23, 6275-6284 (1984).

32. M. Eichner, S. Thoms, S. A. Kranz, B. Rost, Cellular inorganic carbon fluxes in Trichodesmium: a combined approach using measurements and modelling. J Exp Bot 66, 749-759 (2015). https://doi.org/10.1093/jxb/eru427 
33. K. H. Freeman, J. M. Hayes, Fractionation of carbon isotopes by phytoplankton and estimates of ancient $\mathrm{CO}_{2}$ levels. Global Biogeochem Cycles 6, 185-198 (1992). https://doi.org/10.1029/92gb00190

34. S. J. Hurley, B. A. Wing, C. E. Jasper, N. C. Hill, J. C. Cameron, Carbon isotope evidence for the global physiology of Proterozoic cyanobacteria. Sci Adv 7 (2021).

https://doi.org/10.1126/sciadv.abc8998

35. E. B. Wilkes, R. B. Y. Lee, H. L. O. McClelland, R. E. M. Rickaby, A. Pearson, Carbon isotope ratios of coccolith-associated polysaccharides of Emiliania huxleyi as a function of growth rate and $\mathrm{CO}_{2}$ concentration. Org Geochem 119, 1-10 (2018). https://doi.org/10.1016/j.orggeochem.2018.02.006

36. G. G. Tcherkez, G. D. Farquhar, T. J. Andrews, Despite slow catalysis and confused substrate specificity, all ribulose bisphosphate carboxylases may be nearly perfectly optimized. Proc NatI Acad Sci USA 103, 7246-7251 (2006). https://doi.org/10.1073/pnas.0600605103

37. R. A. Studer, P. A. Christin, M. A. Williams, C. A. Orengo, Stability-activity tradeoffs constrain the adaptive evolution of RubisCO. Proc Natl Acad Sci USA 111, 2223-2228 (2014). https://doi.org/10.1073/pnas.1310811111

38. A. I. Flamholz et al., Revisiting trade-offs between Rubisco kinetic parameters. Biochemistry 58, 3365-3376 (2019). https://doi.org/10.1021/acs.biochem.9b00237

39. D. B. McNevin et al., Differences in carbon isotope discrimination of three variants of D-ribulose1,5-bisphosphate carboxylase/oxygenase reflect differences in their catalytic mechanisms. J Biol Chem 282, 36068-36076 (2007). https://doi.org/10.1074/ibc.M706274200

40. B. M. Berla et al., Synthetic biology of cyanobacteria: unique challenges and opportunities. Front Microbiol 4 (2013). https://doi.org/10.3389/fmicb.2013.00246

41. Y. Chen, C. K. Holtman, A. Taton, S. S. Golden, "Functional Analysis of the Synechococcus elongatus PCC 7942 Genome" in Functional Genomics and Evolution of Photosynthetic Systems, R. Burnap, W. Vermaas, Eds. (Springer, Dordrecht, 2012), pp. 119-137.

42. B. Kacar, V. Hanson-Smith, Z. R. Adam, N. Boekelheide, Constraining the timing of the Great Oxidation Event within the Rubisco phylogenetic tree. Geobiology 15, 628-640 (2017). https://doi.org/10.1111/gbi.12243

43. H. S. Yoon, J. D. Hackett, C. Ciniglia, G. Pinto, D. Bhattacharya, A Molecular Timeline for the Origin of Photosynthetic Eukaryotes. Mol Biol Evol 21, 809-818 (2004). https://doi.org/10.1093/molbev/msh075

44. S. Maruyama, E. Kim, "Evolution of Photosynthetic Eukaryotes; Current Opinion, Perplexity, and a New Perspective" in Symbiosis: Cellular, Molecular, Medical and Evolutionary Aspects, M. Kloc, Ed. (Springer, Cham, 2020), pp. 337-351.

45. P. M. Shih et al., Biochemical characterization of predicted Precambrian RuBisCO. Nat Commun 7, 10382 (2016). https://doi.org/10.1038/ncomms10382

46. T. M. Gibson et al., Precise age of Bangiomorpha pubescens dates the origin of eukaryotic photosynthesis. Geology 46, 135-138 (2017). https://doi.org/10.1130/g39829.1

47. S. A. Crowe et al., Atmospheric oxygenation three billion years ago. Nature 501, 535-538 (2013). https://doi.org/10.1038/nature12426

48. A. D. Anbar et al., A whiff of oxygen before the great oxidation event? Science 317, 1903-1906 (2007). https://doi.org/10.1126/science.1140325

49. J. Newman, C. I. Brändén, T. A. Jones, Structure determination and refinement of ribulose 1,5bisphosphate carboxylase/oxygenase from Synechococcus PCC6301. Acta Crystallogr D 49, 548560 (1993). https://doi.org/10.1107/s090744499300530x 
601

602

603

604

605

606

607

608

609

610

611

612

613

614

615

616

617

618

619

620

621

622

623

50. A. K. Garcia et al., System-level effects of $\mathrm{CO}_{2}$ and RuBisCO concentration on carbon isotope fractionation. bioRxiv [Preprint] (2021). https://doi.org/10.1101/2021.04.20.440233 (accessed 28 May 2021).

51. D. C. Catling, K. J. Zahnle, The Archean atmosphere. Sci Adv 6, eaax1420 (2020). https://doi.org/10.1126/sciadv.aax1420

52. T. Zavřel, M. A. Sinetova, D. Búzová, P. Literáková, J. Červený, Characterization of a model cyanobacterium Synechocystis sp. PCC 6803 autotrophic growth in a flat-panel photobioreactor. Eng Life Sci 15, 122-132 (2015). https://doi.org/10.1002/elsc.201300165

53. E. Szekeres, C. Sicora, N. Dragos, B. Druga, Selection of proper reference genes for the cyanobacterium Synechococcus PCC 7002 using real-time quantitative PCR. FEMS Microbiol Lett 359, 102-109 (2014). https://doi.org/10.1111/1574-6968.12574

54. D. S. Kubien, S. M. Whitney, P. V. Moore, L. K. Jesson, The biochemistry of Rubisco in Flaveria. J Exp Bot 59, 1767-1777 (2008). https://doi.org/10.1093/jxb/erm283

55. G. H. Rau, U. Riebesell, D. Wolf-Gladrow, A model of photosynthetic ${ }^{13} \mathrm{C}$ fractionation by marine phytoplankton based on diffusive molecular $\mathrm{CO}_{2}$ uptake. Mar Ecol Prog Ser 133, 275-285 (1996). https://doi.org/10.3354/meps133275

56. W. G. Mook, J. C. Bommerson, W. H. Staverman, Carbon isotope fractionation between dissolved bicarbonate and gaseous carbon dioxide. Earth Planet Sc Lett 22, 169-176 (1974). https://doi.org/10.1016/0012-821x(74)90078-8

57. L. H. Gunn, E. Martin Avila, R. Birch, S. M. Whitney, The dependency of red Rubisco on its cognate activase for enhancing plant photosynthesis and growth. Proc Natl Acad Sci USA 117, 25890-25896 (2020). https://doi.org/10.1073/pnas.2011641117

58. B. Kacar, X. Ge, S. Sanyal, E. A. Gaucher, Experimental Evolution of Escherichia coli Harboring an Ancient Translation Protein. J Mol Evol 84, 69-84 (2017). https://doi.org/10.1007/s00239-017$\underline{9781-0}$

59. M. Goldsmith, D. S. Tawfik, Potential role of phenotypic mutations in the evolution of protein expression and stability. Proc Natl Acad Sci USA 106, 6197-6202 (2009).

https://doi.org/10.1073/pnas.0809506106

60. P.-A. Christin et al., Evolutionary Switch and Genetic Convergence on rbcL following the Evolution of C4 Photosynthesis. Mol Biol Evol 25, 2361-2368 (2008). https://doi.org/10.1093/molbev/msn178

61. B. M. Long, B. Förster, S. B. Pulsford, G. D. Price, M. R. Badger, Rubisco proton production can drive the elevation of $\mathrm{CO}_{2}$ within condensates and carboxysomes. Proc Natl Acad Sci USA 118 (2021). https://doi.org/10.1073/pnas.2014406118

62. R. Burnap, M. Hagemann, A. Kaplan, Regulation of $\mathrm{CO}_{2}$ Concentrating Mechanism in Cyanobacteria. Life 5, 348-371 (2015). https://doi.org/10.3390/life5010348

63. Jeffrey C. Cameron, Steven C. Wilson, Susan L. Bernstein, Cheryl A. Kerfeld, Biogenesis of a Bacterial Organelle: The Carboxysome Assembly Pathway. Cell 155, 1131-1140 (2013). https://doi.org/10.1016/j.cell.2013.10.044

64. D. Shi, Y. Xu, F. M. M. Morel, Effects of the $\mathrm{pH} / \mathrm{pCO}$ control method on medium chemistry and phytoplankton growth. Biogeosciences 6, 1199-1207 (2009). https://doi.org/10.5194/bg-6-1199$\underline{2009}$

65. J. M. Hayes, Factors controlling $13 \mathrm{C}$ contents of sedimentary organic compounds: Principles and evidence. Mar Geol 113, 111-125 (1993). https://doi.org/10.1016/0025-3227(93)90153-m

66. R. R. Bidigare et al., Consistent fractionation of ${ }^{13} \mathrm{C}$ in nature and in the laboratory: growth-rate effects in some haptophyte algae. Global Biogeochem Cycles 11, 279-292 (1997). https://doi.org/10.1029/96gb03939 
656

657

658

659

660

661

662

663

664

665

666

667

668

669

670

67. B. A. Schubert, A. H. Jahren, The effect of atmospheric $\mathrm{CO}_{2}$ concentration on carbon isotope fractionation in $\mathrm{C}_{3}$ land plants. Geochim Cosmochim Acta 96, 29-43 (2012). https://doi.org/10.1016/i.gca.2012.08.003

68. B. Kacar, L. Guy, E. Smith, J. Baross, Resurrecting ancestral genes in bacteria to interpret ancient biosignatures. Philos Trans R Soc A 375 (2017). https://doi.org/10.1098/rsta.2016.0352

69. A. K. Garcia, H. McShea, B. Kolaczkowski, B. Kacar, Reconstructing the evolutionary history of nitrogenases: Evidence for ancestral molybdenum-cofactor utilization. Geobiology 18, 394-411 (2020). https://doi.org/10.1111/gbi.12381

70. A. K. Garcia, B. Kacar, How to resurrect ancestral proteins as proxies for ancient biogeochemistry. Free Radic Biol Med 140, 260-269 (2019). https://doi.org/10.1016/i.freeradbiomed.2019.03.033

71. V. Hanson-Smith, A. Johnson, PhyloBot: A Web Portal for Automated Phylogenetics, Ancestral Sequence Reconstruction, and Exploration of Mutational Trajectories. PLoS Comput Biol 12, e1004976 (2016). https://doi.org/10.1371/journal.pcbi.1004976

72. A. Stamatakis, RAxML version 8: a tool for phylogenetic analysis and post-analysis of large phylogenies. Bioinformatics 30, 1312-1313 (2014). https://doi.org/10.1093/bioinformatics/btu033

73. Z. Yang, PAML 4: phylogenetic analysis by maximum likelihood. Mol Biol Evol 24, 1586-1591 (2007). https://doi.org/10.1093/molbev/msm088

74. Y. Liu, B. Schmidt, D. L. Maskell, MSAProbs: multiple sequence alignment based on pair hidden Markov models and partition function posterior probabilities. Bioinformatics 26, 1958-1964 (2010). https://doi.org/10.1093/bioinformatics/btq338

75. N. Lartillot, H. Philippe, A Bayesian mixture model for across-site heterogeneities in the aminoacid replacement process. Mol Biol Evol 21, 1095-1109 (2004). https://doi.org/10.1093/molbev/msh112

76. S. Whelan, N. Goldman, A general empirical model of protein evolution derived from multiple protein families using a maximum-likelihood approach. Mol Biol Evol 18, 691-699 (2001). https://doi.org/10.1093/oxfordjournals.molbev.a003851

77. F. Abascal, R. Zardoya, D. Posada, ProtTest: selection of best-fit models of protein evolution. Bioinformatics 21, 2104-2105 (2005). https://doi.org/10.1093/bioinformatics/bti263

78. W. M. Fitch, Toward Defining the Course of Evolution: Minimum Change for a Specific Tree Topology. Syst Zool 20 (1971). https://doi.org/10.2307/2412116

79. R. Rippka, J. Deruelles, J. B. Waterbury, M. Herdman, R. Y. Stanier, Generic Assignments, Strain Histories and Properties of Pure Cultures of Cyanobacteria. Microbiology 111, 1-61 (1979). https://doi.org/https://doi.org/10.1099/00221287-111-1-1

80. K. Sprouffske, A. Wagner, Growthcurver: an R package for obtaining interpretable metrics from microbial growth curves. BMC Bioinformatics 17, 172 (2016). https://doi.org/10.1186/s12859$\underline{\text { 016-1016-7 }}$

81. E. M. Clerico, J. L. Ditty, S. S. Golden, Specialized techniques for site-directed mutagenesis in cyanobacteria. Methods Mol Biol 362, 155-171 (2007). https://doi.org/10.1007/978-1-59745257-1 11

82. D. S. Kubien, C. M. Brown, H. J. Kane, Quantifying the amount and activity of Rubisco in leaves. Methods Mol Biol 684, 349-362 (2011). https://doi.org/10.1007/978-1-60761-925-3 27

83. A. J. De Porcellinis et al., Overexpression of bifunctional fructose-1,6bisphosphatase/sedoheptulose-1,7-bisphosphatase leads to enhanced photosynthesis and global reprogramming of carbon metabolism in Synechococcus sp. PCC 7002. Metabolic Engineering 47, 170-183 (2018). https://doi.org/10.1016/i.ymben.2018.03.001 
bioRxiv preprint doi: https://doi.org/10.1101/2021.05.31.446354; this version posted May 31, 2021. The copyright holder for this preprint (which

was not certified by peer review) is the author/funder, who has granted bioRxiv a license to display the preprint in perpetuity. It is made available under aCC-BY-NC-ND 4.0 International license.

671 84. T. Zavřel, M. Sinetova, J. Červený, Measurement of Chlorophyll $a$ and Carotenoids Concentration 672 in Cyanobacteria. Bio-Protocol 5 (2015). https://doi.org/10.21769/BioProtoc.1467

673

674

675 


\section{Figures and Figure Legends}

677

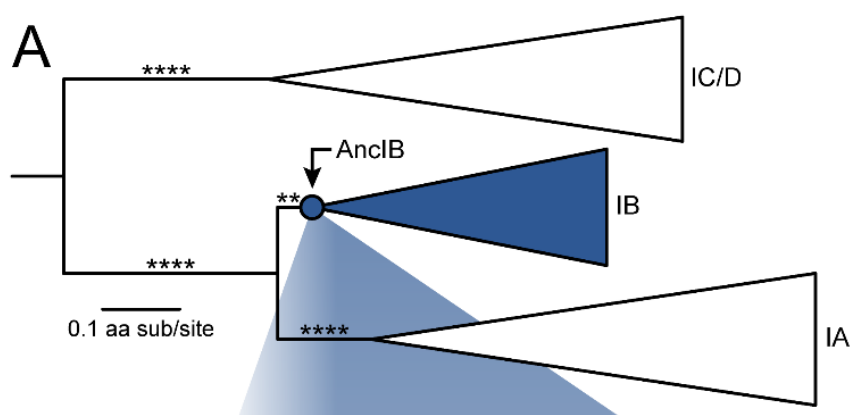

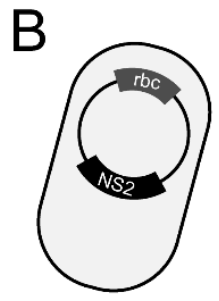

WT

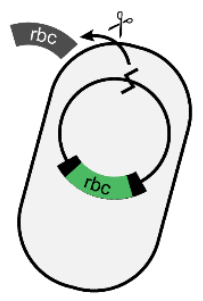

Syn01
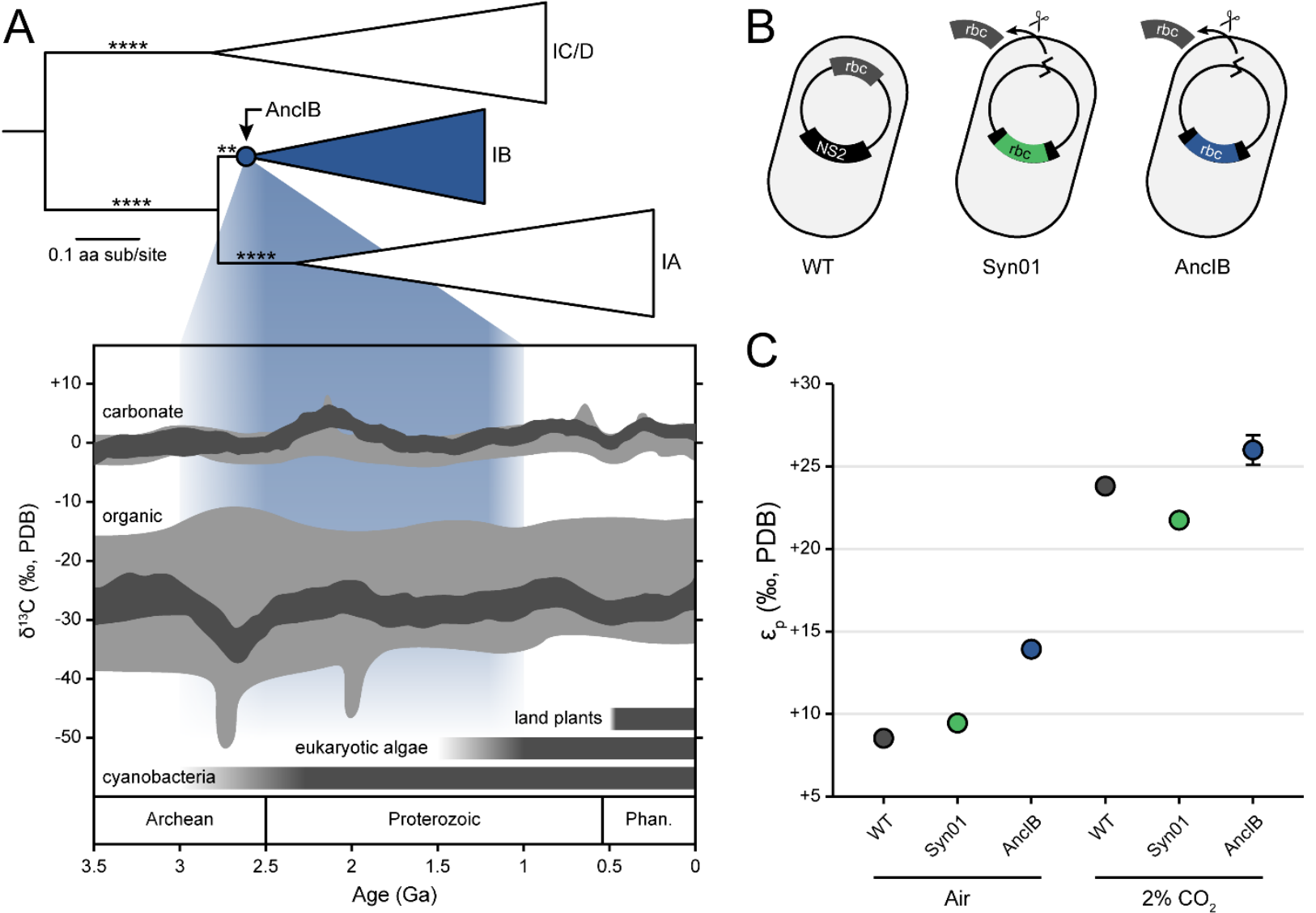

678

679

680

681

682

683

684

685

686

687

688

689

690

691
Figure 1. Reconstruction of ancestral RuBisCO biogeochemical signatures. $(A)$ Maximum likelihood Form I RuBisCO RbcL phylogeny (derived from full RuBisCO phylogeny described in Kacar et al. (42)). Ancestral AncIB node and descendent Form IB clade highlighted in blue. Approximate likelihood ratio (aLR) branch support indicated by asterisks ( $\left.{ }^{* *}:>10, * * * *:>1000\right)$. Carbon isotope record figure adapted from Garcia et al. (21), with data from Schidlowski et al. (25) (grey) and Krissansen-Totton et al. (24) (dark grey). Approximate age range of AnclB indicated by blue field (see text for discussion). ( $B$ ) Genetic engineering of S. elongatus strains. Strain Syn01 was constructed by inserting a second copy of the rbc operon in the chromosomal neutral site 2 (NS2). Strain AnclB was constructed by inserting the genetic sequence encoding for the ancestral AnclB $r b c L$ within the NS2 $r b c$ operon. The native $r b c$ operon was removed in both strains Syn01 and AnclB. (C) Photosynthetic carbon isotope fractionation $\left(\varepsilon_{\mathrm{p}}\right)$ of $S$. elongatus strains in this study, cultured in ambient air or $2 \% \mathrm{CO}_{2} . \mathrm{n}=3$ for each data point and error bars indicate $1 \sigma$ (error bars smaller than some datapoints). 
A

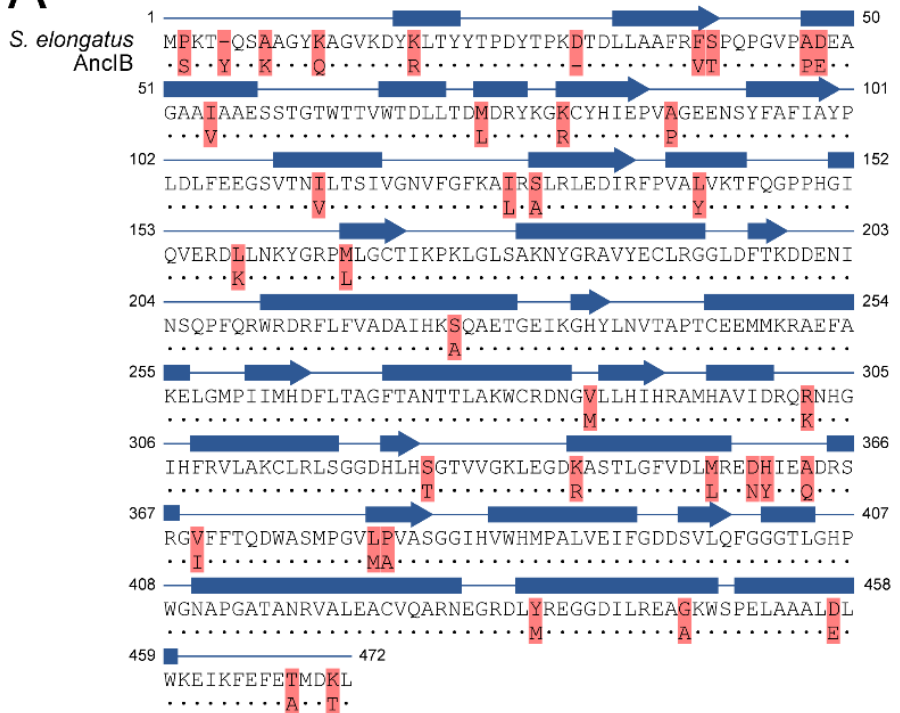

B

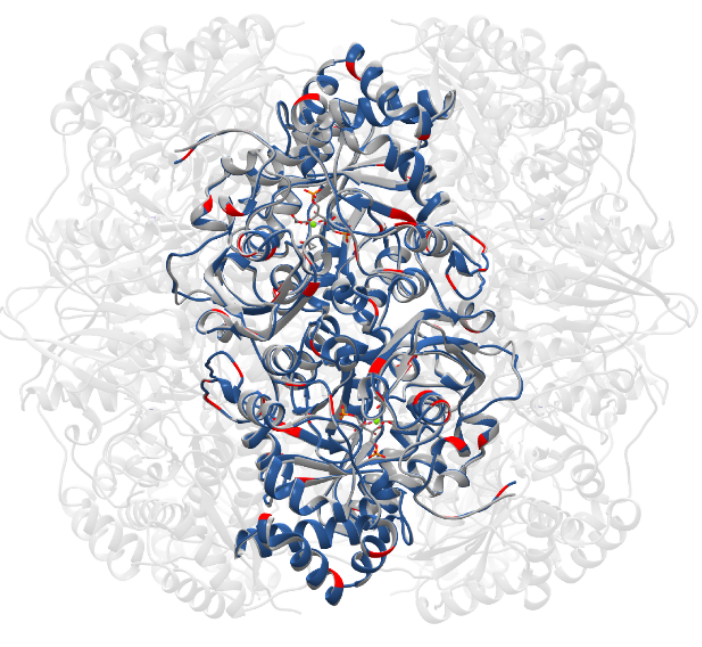

Figure 2. Structure and sequence features of ancestral RuBisCO. (A) Amino acid sequence alignment between ancestral AnclB and extant S. elongatus RbcL. Ancestral site variation relative to the S. elongatus template is highlighted in red. $(B)$ Modeled structure of the ancestral $A n c \mid B L_{2}$ dimer (blue), aligned to the active conformation of the extant $S$. elongatus $\mathrm{L}_{8} \mathrm{~S}_{8}$ hexadecamer (grey; PDB: 1RBL (49)). Highlighted residues in $(A)$ are also highlighted in $(B)$. Site numbering from extant $S$. elongatus. Conserved residues are indicated by dots and secondary structure is indicated above the sequences (blue rectangle: $\alpha$-helix; blue arrow: $\beta$-sheet). 
701

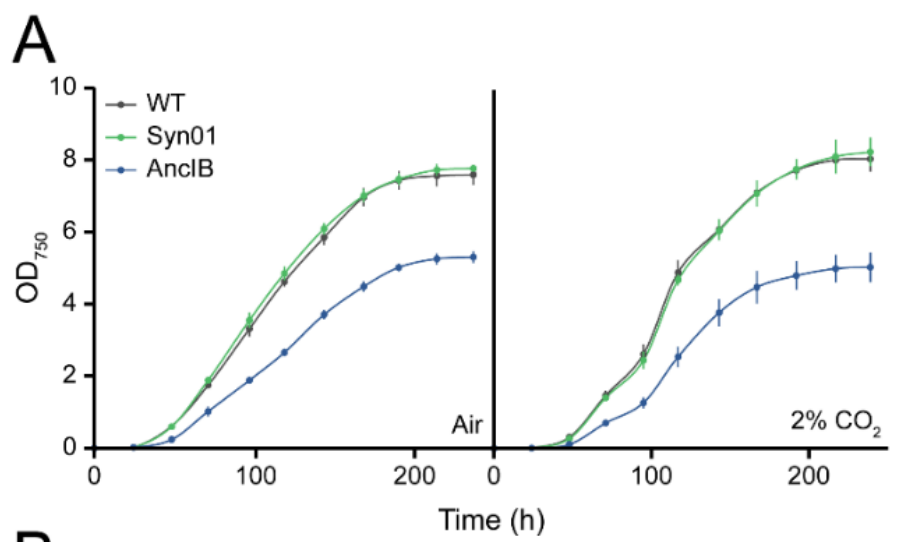

B

Time (h)

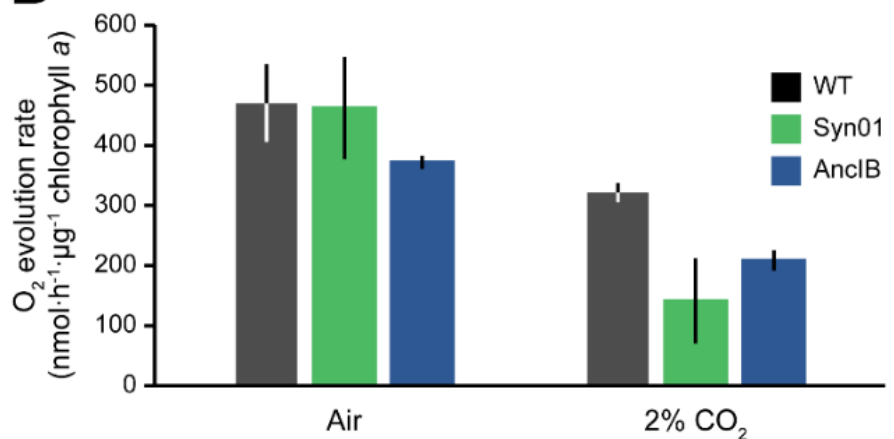

702

703

704

705

706
Figure 3. $(A)$ Growth curves and $(B)$ photosynthetic oxygen evolution of $S$. elongatus strains cultured in ambient air or $2 \% \mathrm{CO}_{2}$. $(A, B) \mathrm{n}=3$ for each data point or bar and error bars indicate $1 \sigma$. 
A
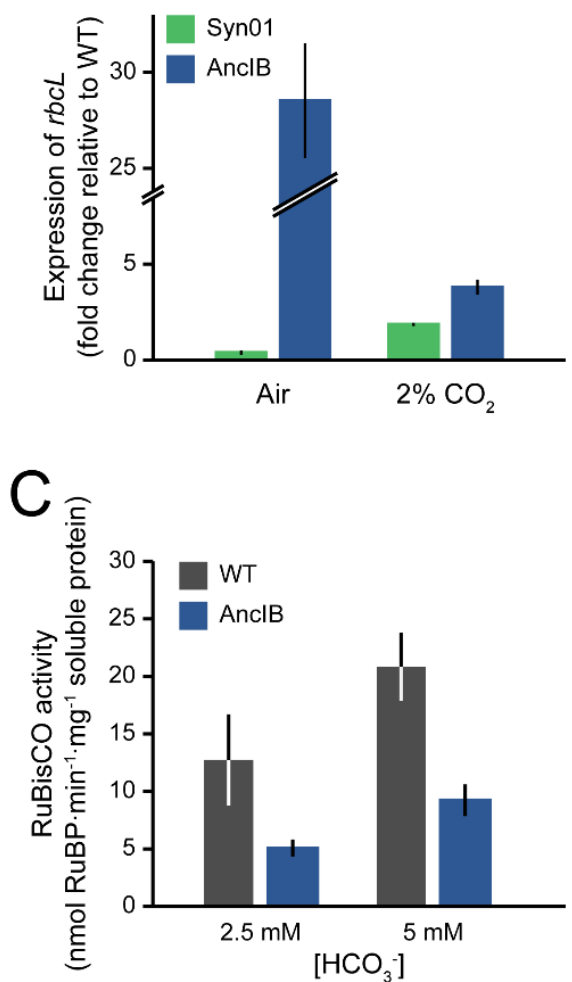

B
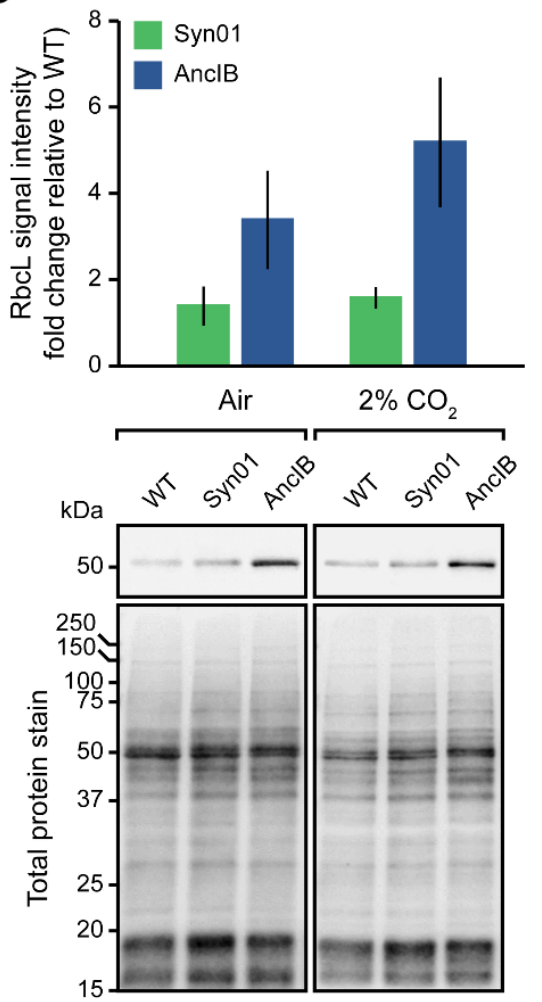

Figure 4. Expression and total cell activity of RuBisCO in S. elongatus strains. (A) Expression of $r b c L$ in Syn01 and AnclB detected by RT-qPCR (secA reference gene), relative to WT. (B) Immunodetection of $\mathrm{RbcL}$ protein. Top, RbcL signal intensities normalized to those for total soluble protein load. Bottom, Western blot showing RbcL protein detected by anti-RuBisCO antibody and total protein stain from crude cell lysates $(C)$ Total cell RuBisCO activity, measured with $2.5 \mathrm{mM}$ and $5 \mathrm{mM} \mathrm{HCO}_{3}{ }^{-}$concentrations. $(A-C) n=3$ for each bar (except $2 \% \mathrm{CO}_{2}$ RbcL signal intensity data, $\mathrm{n}=6$ ) and error bars indicate $1 \sigma$. 


\section{Tables}

Table 1. Strains and plasmids used in this study.

\begin{tabular}{|c|c|c|c|}
\hline Strain or plasmid & Description/Genotype & $\begin{array}{l}\text { Antibiotic } \\
\text { resistance }\end{array}$ & Source/Reference \\
\hline WT & $\begin{array}{l}\text { Wild-type strain of S. elongatus } \\
\text { PCC } 7942\end{array}$ & - & $\begin{array}{l}\text { Susan S. Golden } \\
\text { (UC San Diego) }\end{array}$ \\
\hline Syn01 & $\begin{array}{l}\text { S. elongatus strain Syn02 with the } \\
\text { native } r b c \text { operon removed: Syn02 } \\
\text { and } \Delta(r b c L-r b c S-p u r K):: a a d A \text {. }\end{array}$ & $\begin{array}{l}\mathrm{Km}, \\
\mathrm{Sp}+\mathrm{Sm}\end{array}$ & (50) \\
\hline Syn02 & $\begin{array}{l}\text { S. elongatus PCC } 7942 \text { carrying a } \\
\text { second copy of the } r b c \text { operon and } \\
\text { flanking sequences at NS2: } \\
\text { NS2::aphl-rbcL-rbcS-purK- } \\
\text { Synpcc7942_1429- } \\
\text { Synpcc7942_1430 }\end{array}$ & $\mathrm{Km}$ & (50) \\
\hline Syn03 & $\begin{array}{l}\text { S. elongatus PCC } 7942 \text { carrying a } \\
\text { modified copy of the rbc operon } \\
\text { (with the ancestral } r b c L \text { ) and } \\
\text { flanking sequences at NS2: } \\
\text { NS2::aphI-anclB-rbcS-purK- } \\
\text { Synpcc7942_1429- } \\
\text { Synpcc7942_1430 }\end{array}$ & $\begin{array}{l}\mathrm{Km}, \\
\mathrm{Sp}+\mathrm{Sm}\end{array}$ & This study \\
\hline AnclB & $\begin{array}{l}\text { S. elongatus strain Syn03 carrying } \\
\text { the ancestral AnclB } r b c L \text { gene in } \\
\text { the } r b c \text { operon copy at NS2 and } \\
\text { having the native } r b c \text { operon } \\
\text { replaced with a Sp/Sm resistance } \\
\text { gene: } \Delta(r b c L-r b c S-p u r K):: a a d A \text {. }\end{array}$ & $\mathrm{Km}$ & This study \\
\hline pSyn01 & $\begin{array}{l}\text { Plasmid to replace } S \text {. elongatus' } \\
\text { native } r b c \text { operon (CP000100: } \\
\text { 1479070-1482595) with a Sp/Sm } \\
\text { resistance gene: } \Delta(r b c L-r b c S- \\
\text { purK)::aadA. }\end{array}$ & $\mathrm{Sp}+\mathrm{Sm}$ & This study \\
\hline pSyn02 & $\begin{array}{l}\text { Plasmid for recombination at NS2 } \\
\text { of } S \text {. elongatus chromosome } \\
\text { carrying the } r b c \text { operon including } \\
r b c L, r b c S, \text { purK, and flanking } \\
\text { sequences from S. elongatus PCC } \\
7942 \text { (CP000100: 1479071- } \\
1484283 \text { ) }\end{array}$ & $\mathrm{Km}$ & (50) \\
\hline pSyn03 & $\begin{array}{l}\text { pSyn02 in which the coding } \\
\text { sequence of RbcL was replaced } \\
\text { with the coding sequence of AnclB }\end{array}$ & $\mathrm{Km}$ & This study \\
\hline
\end{tabular}


bioRxiv preprint doi: https://doi.org/10.1101/2021.05.31.446354; this version posted May 31, 2021. The copyright holder for this preprint (which

was not certified by peer review) is the author/funder, who has granted bioRxiv a license to display the preprint in perpetuity. It is made available under aCC-BY-NC-ND 4.0 International license.

Table 2. Growth parameters of $S$. elongatus strains. Values represent the mean of three replicates $\pm 1 \sigma$. Asterisks indicate significance relative to WT for the same atmospheric condition, determined by oneway ANOVA and post-hoc Tukey HSD tests (**: $\left.p<0.01 ;{ }^{* * *}: p<0.001\right)$.

726

\begin{tabular}{|c|c|c|c|c|}
\hline Strain & Atmosphere & Doubling time $(\mathrm{h})$ & Midpoint time (h) & Maximum cell density $\left(O D_{750}\right)$ \\
\hline WT & \multirow[t]{3}{*}{ Air } & $18.9 \pm 1.0$ & $106.4 \pm 2.8$ & $7.7 \pm 0.3$ \\
\hline Syn01 & & $18.6 \pm 0.3$ & $103.8 \pm 1.9$ & $7.7 \pm 0.1$ \\
\hline AnclB & & $20.5 \pm 0.4$ & $118.4 \pm 2.1^{* *}$ & $5.4 \pm 0.2 * * *$ \\
\hline WT & \multirow[t]{3}{*}{$2 \% \mathrm{CO}_{2}$} & $16.9 \pm 1.5$ & $110.8 \pm 6.1$ & $8.0 \pm 0.3$ \\
\hline Syn01 & & $17.3 \pm 1.0$ & $113.9 \pm 2.3$ & $8.1 \pm 0.5$ \\
\hline AnclB & & $15.8 \pm 0.5$ & $117.8 \pm 1.7$ & $5.0 \pm 0.4^{* * *}$ \\
\hline
\end{tabular}

727

728 


\section{Supplemental Information}

731

732

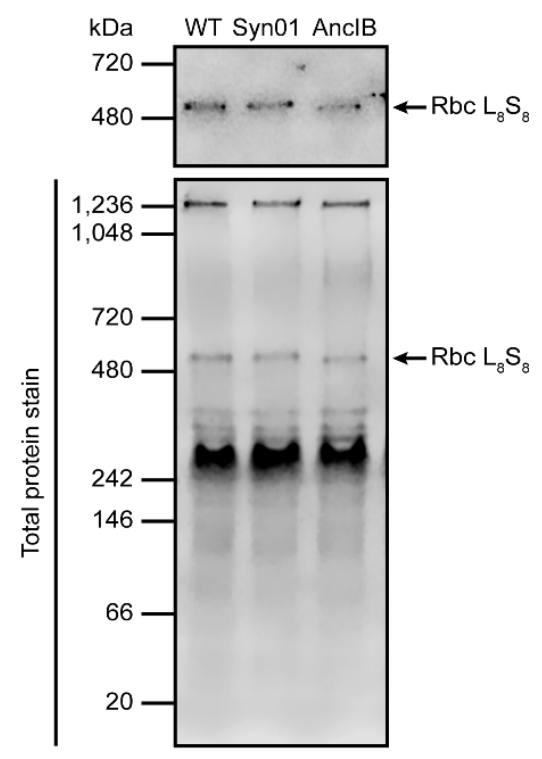

Figure S1. Immunodetection of assembled RuBisCO. Western blot showing the assembly of RbcL (WT and AnclB) and RbcS into the $\mathrm{L}_{8} \mathrm{~S}_{8}$ hexadecameric complex $(520 \mathrm{kDa})$, detected by anti-RbcL antibody.

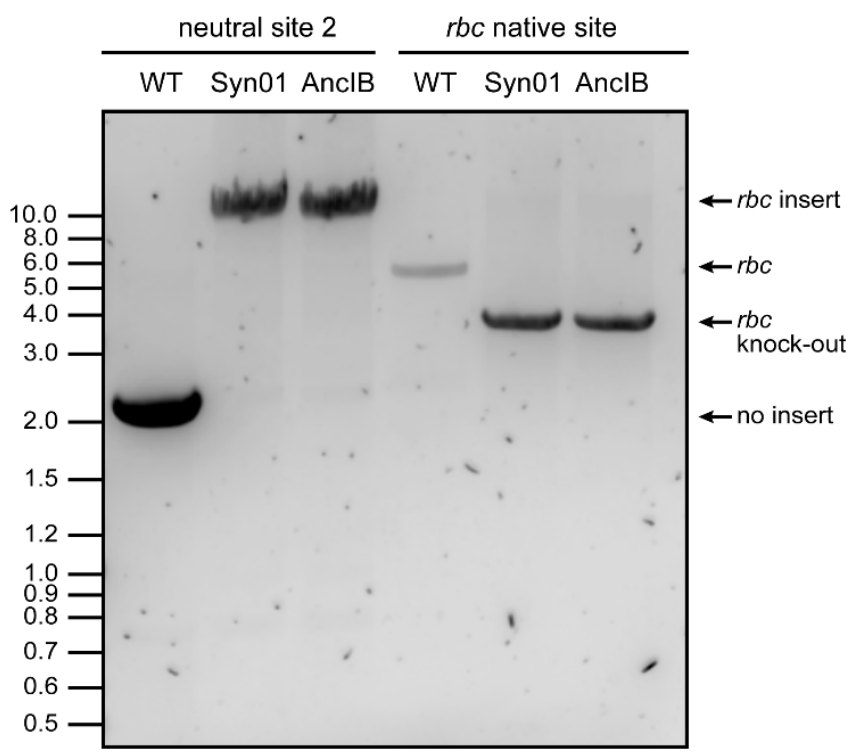

Figure S2. Genotyping of S. elongatus strains. Primers F06/R06 (Table S2) were used to confirm the rbc operon insertion at the neutral site 2 (NS2), either with WT rbcL (for Syn01) or AnclB rbcL ( $r b c$ insert: $8,617 \mathrm{bp}$; no insert: 1,970 bp). Primers F07/R07 were used to confirm the presence or absence of the rbc operon at the native site ( $r b c$ present at its native site: 5,140 bp; $r b c$ knocked out and replaced with the aadA gene: 3,342 bp). 
Table S1. Isotopic composition of biomass and DIC in growth medium of S. elongatus cultures.

\begin{tabular}{|l|l|l|l|l|l|}
\hline Strain & Atmosphere & $\delta^{13} C_{\text {biomass }}(\% \circ)$ & $\delta^{13} C_{\text {DIC }}(\% \circ)$ & $\delta^{13} C_{\text {CO2 }}(\% \circ)$ & {$[\mathrm{DIC}](\mathrm{mM})$} \\
\hline \multirow{3}{*}{ WT } & Air & $-19.63 \pm 0.07$ & $-2.92 \pm 0.02$ & $-11.28 \pm 0.02$ & $5.14 \pm 0.07$ \\
\cline { 2 - 6 } & $2 \% \mathrm{CO}_{2}$ & $-26.41 \pm 0.15$ & $5.77 \pm 0.30$ & $-2.59 \pm 0.30$ & $7.35 \pm 0.24$ \\
\hline \multirow{3}{*}{ Ayn01 } & Air & $-20.20 \pm 0.19$ & $-2.63 \pm 0.10$ & $-11.00 \pm 0.10$ & $5.23 \pm 0.02$ \\
\cline { 2 - 6 } & $2 \% \mathrm{CO}_{2}$ & $-26.84 \pm 0.10$ & $3.29 \pm 0.25$ & $-5.07 \pm 0.25$ & $7.53 \pm 0.34$ \\
\hline \multirow{2}{*}{ AnclB } & Air & $-20.60 \pm 0.08$ & $1.26 \pm 0.10$ & $-7.10 \pm 0.10$ & $3.44 \pm 0.05$ \\
\cline { 2 - 6 } & $2 \% \mathrm{CO}_{2}$ & $-31.2 \pm 0.34$ & $3.15 \pm 0.62$ & $-5.21 \pm 0.62$ & $5.70 \pm 0.70$ \\
\hline
\end{tabular}

Table S2. Primers used in this study.

\begin{tabular}{|c|c|c|}
\hline Primer $^{\mathrm{a}}$ & Sequence (5'-3') & Description \\
\hline F06 & GACAATCCTGTTCTCCGGCA & \multirow{2}{*}{$\begin{array}{l}\text { Genotyping S. elongatus strains to screen for the } \\
\text { rbc operon insert (either with native or AnclB } r b c L \text { ) } \\
\text { at NS2 (PCR product size: with } r b c \text { insert }-8,617 \\
\text { bp, without } r b c \text { insert }-1,970 \mathrm{bp} \text { ). }\end{array}$} \\
\hline R06 & ATCAACGCCGTACCCGTATC & \\
\hline F07 & GGAGTCAATTCTGCAAGAGC & \multirow[b]{2}{*}{$\begin{array}{l}\text { Genotyping } S \text {. elongatus strains to confirm the } \\
\text { presence or absence of the } r b c \text { operon at the } \\
\text { native site (PCR product size: with the } r b c \text { operon } \\
-5,140 \mathrm{bp} \text {, without the } r b c \text { operon }-3,342 \mathrm{bp} \text { ) R07 } \\
\text { was also used to sequence the native } r b c \text { operon } \\
\text { deletion site. }\end{array}$} \\
\hline R07 & TCAAGCTCGGTCTACTGC & \\
\hline F08 & GAATGCTCCGCTGGACTTGC & \multirow{2}{*}{$\begin{array}{l}\text { Sequencing the } r b c \text { operon insertion site at NS2. } \\
\text { F08 was also used to sequence the native } r b c \\
\text { operon deletion site. }\end{array}$} \\
\hline R08 & TGTACTCGATTTGTGCAGCG & \\
\hline F09 & ACCACCTTGGCAAAATGGTG & \multirow{2}{*}{$\begin{array}{l}\text { qPCR analysis of the expression of } r b c L \text { (ID: } \\
\text { Synpcc7942_1426) that encodes the RuBisCO } \\
\text { large subunit. }\end{array}$} \\
\hline R09 & TTTGTCGCCTTCCAGTTTGC & \\
\hline F11 & ATTACCTGCGCGACAACATG & \multirow{2}{*}{$\begin{array}{l}\text { qPCR analysis of the expression of } \sec A \text { (reference } \\
\text { gene, ID: Synpcc7942_0289) that encodes the } \\
\text { preprotein translocase subunit SecA. }\end{array}$} \\
\hline R11 & TGCCCGCATGTATTTTTCGC & \\
\hline F13 & GGAGCCTCTGACTATCGCTGGGGGAG & \multirow{2}{*}{$\begin{array}{l}\text { Linearization of pSyn02 without the } r b c L \text { coding } \\
\text { sequence. }\end{array}$} \\
\hline R13 & GTCGTCTCTCCCTAGAGATATG & \\
\hline F14 & AAACCGGCGAAATCAAAGGC & \multirow{2}{*}{$\begin{array}{l}\text { qPCR analysis of the expression of AnclB rbcL that } \\
\text { encodes the AnclB RuBisCO large subunit. }\end{array}$} \\
\hline R14 & CGTGCATGATGATGGGCATG & \\
\hline F15 & TGTTTGAAGAAGGCAGCGTG & \multirow{2}{*}{$\begin{array}{l}\text { Sequencing the internal region of AnclB rbcL } \\
\text { inserted at NS2. }\end{array}$} \\
\hline F16 & CCAAATGGTGCCGCGATAAC & \\
\hline
\end{tabular}

